\title{
Effect of Mind/ Body Interventions on Levels of Anxiety, Stress and Depression Among Future Primary School Teacher: A Controlled Study
}

\author{
José Gallego ${ }^{1}$, José M. Aguilar-Parra ${ }^{1}$, Adolfo J. Cangas ${ }^{1}$, Antonio Rosado ${ }^{2}$, \\ and Álvaro I. Langer ${ }^{3,4}$ \\ ${ }^{1}$ Universidad de Almería (España), ${ }^{2}$ Universidad de Lisboa (Portugal), \\ ${ }^{3}$ Pontificia Universidad Católica de Chile and ${ }^{4}$ Red de Salud Mental RedGesam (Chile)
}

\begin{abstract}
The present study compares the effects of three mind/body programs on stress, anxiety and depression among a sampling of university students. These three programs, which are currently experiencing great popularity, are Mindfulness, Tai Chi and Yoga. 282 undergraduate teaching students participated in this research. They were chosen as candidates because, in the future, as working professionals they will be exposed to high levels of stress and, at present, as students they suffer high levels of anxiety during exam periods. 85 students were randomly assigned to a Yoga group, 68 to a Tai Chi group, 84 to a Mindfulness group, and 45 comprised the control group. Tai Chi and Yoga significantly reduced anxiety, while Mindfulness had the same effect on stress; nevertheless, all three programs proved effective in the reduction of psychological malaise in comparison with the control group. In terms of general mental health, Mindfulness produced greater overall effects. The control group did not experience any significant changes in relation to the variables evaluated, and the levels of said variables even worsened according to the post-test conducted prior to the exam period.
\end{abstract}

Keywords: $\operatorname{mind} /$ body interventions, education, stress, anxiety, depression.

\section{Resumen}

En el presente estudio se compara el efecto de tres programas mente/cuerpo que gozan de amplia popularidad en la actualidad, como son Mindfulness, Taichí y Yoga, en el estrés, ansiedad y depresión de una muestra de estudiantes universitarios. En concreto, tomaron parte de la presente investigación 282 estudiantes de Magisterio que, como profesionales, estarán sometidos a altos niveles de estrés, y como alumnos y alumnas, sufren niveles preocupantes de ansiedad en los periodos de examen. Se asignaron aleatoriamente 85 alumnos y alumnas al grupo de Yoga, 68 al grupo de Taichí, 84 al grupo de Mindfulness y 45 al grupo control. Taichí y yoga redujeron significativamente la ansiedad, mientras que Mindfulness el estrés; no obstante, los tres programas fueron efectivos en la reducción del malestar psicológico en comparación con el grupo control. En salud mental general Mindfulness ofreció un mayor efecto. El grupo control no experimentó ningún cambio significativo en las variables evaluadas e incluso hubo un empeoramiento en el postest realizado previamente al periodo de exámenes.

Palabras clave: intervenciones mente/cuerpo, educación, estrés, ansiedad, depresión.

Acknowledgements: A.I. Langer was supported by the Chilean National Fund for Scientific and Technological Development, CONICYT/PAI, Project N. ${ }^{\circ} 82130055$ and by the Fund for Innovation and Competitiveness (FIC) of the Chilean Ministry of Economy, Development and Tourism, through the Millennium Scientific Initiative, Grant N. ${ }^{\circ}$ IS130005.

Correspondence concerning this article should be addressed to José M. Aguilar-Parra, Departamento de Psicología, Universidad de Almería, Ctra. de Sacramento, s/n, 04120. La Cañada de San Urbano, Almería.E-mail: jmaguilar@ual.es 


\section{Introduction}

Recent decades have shown an increase in the research of mindbody interventions as treatment for various mental health problems such as chronic stress, depression and anxiety. These interventions include tai chi, yoga and mindfulness-based therapies (Mehling et al., 2011).

Some of the central mechanisms of action of these interventions involve a synergistic collaboration between care management, body awareness and emotional management, resulting in an increase in both psychological flexibility and psychological wellbeing (Langer, Ulloa, Cangas, Rojas, \& Krause, 2015).

Most notably, mindfulness, which can be summarized as "paying attention in a particular way: on purpose, in the present moment, and non-judgmentally" (KabatZinn, 1994, p. 15), is a secular form of meditation that has been popularized in the West through standardized eight-week programs like Mindfulness Based Stress Reduction (MBSR; Kabat-Zinn, 1990), and Mindfulness Based Cognitive Therapy (MBCT; Segal, Williams, and Teasdale, 2002). Both interventions (MBSR or MBCT) have broad empirical support for the treatment of diverse mental health issues like depression and anxiety (see, for example, Hofmann, Sawyer, \& Witt, 2010), as well as an increase in psychological wellness and quality of life in clinical and nonclinical populations.

The practice of mindfulness meditation is encouraged using two varieties. The first variety is known as "formal" (i.e. seated meditation); and the second, "informal", refers to the completion of daily activities or tasks in a mindful way (Baer, 2003).

However, there are additional mind-body techniques, such as yoga and tai chi. Yoga is a practice that originated in India. While there are currently different versions or types of yoga, Hatha yoga is considered to be the foundation of all other styles, and it is the variety that has received the most scientific attention (Salmon, Lush, Jablonski, \& Sephton, 2009). Recent studies have shown yoga's effectiveness for issues like depression, anxiety and chronic pain (Dick, Niles, Street, Dimartino, \& Mitchell, 2014; Louie, 2014).

Conversely, according to Yeh, Wang, Wayne and Phillips (2008), tai chi has its origins in ancient Chinese martial arts and combines slow physical movements with meditation, body awareness, imagery and attention to breathing. Tai chi offers clear evidence that proves its effectiveness in managing chronic illnesses like pain, cardiovascular disease, arthritis, among others (see, for example, Wang, Collet, \& Lau, 2004). However, limited studies have focused on evaluating tai chi's impact on stress, self-esteem, mood, or quality of life in healthy populations (Zheng et al., 2014). 
While these techniques share common attributes and have proven their effectiveness in treating a variety of issues, they also differ in structure, types of interventions and theoretical emphasis. To the extent known, there are no studies that have compared these three interventions under a randomized controlled design.

In the field of education, various studies have also focused on how these techniques can impact students' emotional wellbeing and level of stress. While the results of these studies were generally favorable with regard to mindfulness (De la Fuente, Franco, \& Mañas, 2010; Oman, Shapiro, Thoresen, Plante, \& Flinders, 2008), yoga (Vernet \& Nicolaci, 2013) and tai chi (Lee et al., 2013), there are no comparative studies of these different methods.

The aim of the present study was to determine the effect of widely popular mind-body programs. Taking into account the status of the issue and the scope of the study, the hypothesis of this trial suggests that three methods based on mind-body interventions (tai chi, yoga and mindfulness) can contribute to a reduction in emotional distress in future teachers when compared to the control group. While evidence exists on the effectiveness of these interventions, no comparative studies have been conducted to date. Therefore, no prior determination has been made on whether one technique is more effective than an- other. Specifically, the results obtained in the present study are expected to elucidate which method can be more effective for every mental health issue.

A specific focus will be placed on evaluating which programs can be more effective in reducing mental health problems among a group of teaching students. The group is comprised of male and female students from the School of Education who, as professionals, will be subjected to a high level of teachingrelated stress (Extremera, Rey, \& Pena, 2010; Moriana \& Herruzo, 2004), and, as students, often experience high levels of anxiety when facing exams (Alvarez, Aguilar, \& Lorenzo, 2012). In addition, the students can learn these techniques and later apply them on their future students. Thus, it is recommended that they be provided with resources to handle this situation (Franco, 2010; Franco, Mañas, Cangas, Moreno, \& Gallego, 2010).

\section{Method}

\section{Participants}

A total of 282 male and female students took part in the present study. The students were enrolled in a first-year teaching course at the University of Almeria (Spain). There was a total of 128 men (45.4\%) and 154 women (54.6\%). Ages ranged from 18 to 49 years $(M=20.33 ; S D=1.55)$. Among the 
group of participating students, 85 were randomly assigned to the yoga group, 68 were assigned to tai chi, 84 were assigned to the mindfulness group and 45 were assigned to the control group (the study initially began with 307 people enrolled in four different first-year primary education courses where each group was randomly assigned to a different program). The first group originally consisted of 85 male and female students, 74 in tai chi, 85 in mindfulness and 63 in the control group, thus indicating an abandonment rate of $8.14 \%$. Additional details on the sampling are provided in the procedure section. There were no significant differences in age or gender among the different groups $(p>.05)$. The exclusion criteria were non-acceptance of the informed consent form to participate in the study and systematic non-attendance in the program (more than $80 \%$ of the sessions).

\section{Measures}

Depression Anxiety Stress Scales (DASS-21) (Lovibond \& Lovibond, 1995). This instrument is made up of 21 items that are rated on a four-point Likert scale ranging from 0 ("Did not apply to me at all over the last week") to 3 ("Applied to me very much or most of the time"), whereby participants indicated what they experienced or felt during the past week. The items are distributed into three subscales (each containing seven items): de- pression, anxiety and stress. The depression subscale indicates that ratings from 0-9 are normal, 10-13 are mild, 14-20 are moderate, 21-27 are severe and 28 or more are extremely severe. The anxiety subscale rates 0-7 as normal, 8-9 as mild, 10-14 as moderate, $15-19$ as severe and 20 or higher as extremely severe. Finally, the stress subscale classifies 0-14 as normal, 15-18 as mild, 1925 as moderate, 26-33 as severe and 34 or higher as extremely severe. The Spanish version validated by Fonseca, Paino, Lemos, and Muñiz (2010) was used. This version was validated in Spanish universities. Results indicated that the levels of internal consistency in the DASS21 subscales were the following: .80 in depression, .73 in anxiety, and .81 in stress. The total DASS21 score resulted in a Cronbach's alpha of 90 .

\section{Procedure}

Prior to signing the informed consent form, participants were assigned to an intervention that consisted of 16 sessions based on specific techniques in tai chi, yoga and mindfulness, as well as a control group. Randomization followed a non-probability convenience sampling, where each group corresponded to a different undergraduate-level course in primary education (1A Yoga, 1B Tai Chi, 1C Mindfulness and 1D Control Group). Sessions were scheduled for 30 minutes twice a week. 
An experimental design was used. A pretest was given at the beginning of the three-month course and a post-test was administered two weeks prior to the start of final exams and oral presentations. All sessions were conducted after school hours.

Mindfulness program: The mindfulness experimental group received an intervention based on Mindfulness Based Cognitive Therapy (MBCT) (Segal et al., 2002), applied in Gallego, AguilarParra, Cangas, Langer, and Mañas (2014). Each session lasted 30 minutes and followed the main structure and components of MBCT in non-clinical populations (Langer, Cangas, \& Gallego, 2010). Specifically, participants were trained in body scanning, mindful breathing, 3-minute breathing space, and seated meditation exercises. Metaphors and poetry were also used to illustrate the main principles and concepts of mindfulness. In addition, participants were provided with body scan and seated meditation audio (in MP3 format) for practice at home.

The yoga program followed Quintero, Rodriguez, Guzman, Llanos, and Reyes (2011). The program consisted of a set of seven poses and counter poses. Participants were given short, repetitive and easy-to-understand instructions to properly work on both left and right hemispheric laterality. Each session lasted 30 minutes and consisted of warm-up exercises, vari- ous Hatha yoga postures like the Seated Forward Bend for improved flexibility, the Tree for balance, the Warrior for strength, the Cat Tilt for breathing, and the Shoulder Stand for brain oxygenation and venous return. The sessions concluded with a relaxation phase. Throughout the entire class, the instructor stressed aspects such as breathing and selfawareness when practicing the postures by repeating instructions and using words like "attention" and "concentration", demonstrating the exercises and providing correction and visual feedback for each posture.

The tai chi program was conducted according to Tsung-Hwa (2001) and Canneti (2008). Each session was carried out in five phases. The first phase focused on concentrated breathing exercises: slow, deep breathing for improved mental concentration; feet separated shoulder-width apart; hands placed on the lower abdomen below the navel and pushing lightly; slow inhale and exhale through the nose with lips loosely closed, feeling the movement of the $a b$ domen. The second phase aimed to improve concentration and progressive relaxation of every part of the body, from the feet up to the head: breathing and relaxation of each part of the body; breathing in static postures and dynamic balance movements; imbalanced and rebalanced movements, both static and dynamic. The objectives of the third phase were to learn a ba- 
sic stance called "rooting", where the feet support the body by acting as roots of a tree, and to maintain proper balance during movements utilizing upper and lower extremities. The fourth phase focused on developing small and large postural structures through short, medium and long ranges of movement in the joints and varying the height of the body's center of gravity. The fifth phase was based on the application of different body movement rhythms: first, slow and constant movements that engage the joints, as per the criterion established by the Yang style; and second, a combination of movements ranging from very slow to explosive, according to the Chen style.

Daily practice of the three techniques was strongly recommended but was not a requirement to continue with the program. The programs were led by three different therapists, each with more than four years of experience in tai chi, yoga and mindfulness techniques.

Finally, the control group was only given pretest and post-test surveys without any type of intervention.

\section{Data analysis}

A first analysis compared pretest and post-test measurements from each group using the Student's t-distribution for related samples. Cohen's $d$ was also used to evaluate the magnitude of the change caused by the intervention. Additionally, the percentage of change between pretest and post-test scores from the different groups was calculated. The one-way ANOVA was used to determine the existence of statistically significant differences in pretest and post-test measurements among the groups. This technique was complemented by evaluating the effect size and corresponding eta squared. Lastly, a MANCOVA analysis was used to evaluate the influence of variables like gender and age (the analyses were conducted using SPSS 21.0).

\section{Results}

Table 1 illustrates the means and standard deviations of the study variables that corresponded to the experimental groups (mindfulness, tai chi and yoga) and control group in each phase of the study.

Tai chi and yoga were significantly effective in reducing anxiety, while mindfulness was significantly effective in reducing stress. Yet, when taking the effect size into account, all three programs contributed to a reduction in both anxiety and stress (yoga slightly less in stress). Finally, the DASS total (general mental health) indicated that mindfulness had a greater effect, followed by yoga and tai chi, respectively. The control group showed no significant change in any of the variables evaluated, and even performed worse on the post-test. This was also the case with the rest of the groups, 
Table 1

Differences in the DASS-21 Scales Before and After Intervention in Experimental and Control Groups

\begin{tabular}{|c|c|c|c|c|c|c|c|c|c|c|}
\hline & \multicolumn{5}{|c|}{ Mindfulness } & \multicolumn{5}{|c|}{ Taichí } \\
\hline & Pretest & Post test & & Pre-Post & & Pretest & Post test & & Pre-Post & \\
\hline & $\begin{array}{c}M \\
(S D)\end{array}$ & $\begin{array}{c}M \\
(S D)\end{array}$ & $t$ & $p$ & $d$ & $\begin{array}{c}M \\
(S D)\end{array}$ & $\begin{array}{c}M \\
(S D)\end{array}$ & $t$ & $p$ & $d$ \\
\hline Depression & $\begin{array}{c}6.40 \\
(3.82)\end{array}$ & $\begin{array}{c}6.48 \\
(2.83)\end{array}$ & -0.187 & .852 & .023 & $\begin{array}{c}6.00 \\
(4.96)\end{array}$ & $\begin{array}{c}7.64 \\
(5.01)\end{array}$ & -1.751 & .085 & -.328 \\
\hline Anxiety & $\begin{array}{l}11.14 \\
(8.23)\end{array}$ & $\begin{array}{c}9.75 \\
(5.89)\end{array}$ & 1.416 & .160 & .300 & $\begin{array}{l}12.96 \\
(8.42)\end{array}$ & $\begin{array}{l}10.12 \\
(5.67)\end{array}$ & 2.905 & .005 & .395 \\
\hline Stress & $\begin{array}{l}10.89 \\
(4.18)\end{array}$ & $\begin{array}{c}9.36 \\
(3.89)\end{array}$ & 2.755 & .007 & .378 & $\begin{array}{l}12.12 \\
(7.00)\end{array}$ & $\begin{array}{l}10.54 \\
(4.48)\end{array}$ & 1.447 & .153 & .268 \\
\hline \multirow[t]{2}{*}{ DASS Total } & $\begin{array}{c}28.48 \\
(14.32)\end{array}$ & $\begin{array}{c}25.27 \\
(10.37)\end{array}$ & 1.853 & .067 & .256 & $\begin{array}{c}31.09 \\
(14.96)\end{array}$ & $\begin{array}{c}28.41 \\
(12.39)\end{array}$ & 1.269 & .209 & .195 \\
\hline & \multicolumn{5}{|c|}{ Yoga } & \multicolumn{5}{|c|}{ Control Group } \\
\hline Depression & $\begin{array}{c}4.64 \\
(4.87)\end{array}$ & $\begin{array}{c}5.06 \\
(6.18)\end{array}$ & -0.670 & .505 & -.075 & $\begin{array}{c}6.47 \\
(5.52)\end{array}$ & $\begin{array}{c}7.94 \\
(5.85)\end{array}$ & -1.541 & .132 & -.258 \\
\hline Anxiety & $\begin{array}{l}12.96 \\
(8.63)\end{array}$ & $\begin{array}{c}9.79 \\
(7.86)\end{array}$ & 3.670 & .000 & .399 & $\begin{array}{l}11.62 \\
(6.77)\end{array}$ & $\begin{array}{l}13.62 \\
(6.33)\end{array}$ & -1.807 & .079 & -.305 \\
\hline Stress & $\begin{array}{l}12.46 \\
(5.72)\end{array}$ & $\begin{array}{l}11.50 \\
(7.80)\end{array}$ & 1.142 & .257 & .164 & $\begin{array}{l}11.78 \\
(6.20)\end{array}$ & $\begin{array}{l}12.21 \\
(6.83)\end{array}$ & -0.345 & .732 & -.166 \\
\hline DASS Total & $\begin{array}{c}30.07 \\
(17.23)\end{array}$ & $\begin{array}{c}26.36 \\
(19.39)\end{array}$ & 1.954 & .054 & .221 & $\begin{array}{c}29.72 \\
(15.34)\end{array}$ & $\begin{array}{c}34.21 \\
(16.56)\end{array}$ & -1.644 & .109 & -.281 \\
\hline
\end{tabular}

as the post-test was administered prior to the start of final exams.

The mean difference between the pretest measurements across the different groups, as shown in Table 2 , did not reflect any initial statistically significant differences among the groups in any of the variables analyzed. However, the post-test differences did show statistically significant differences among all groups in all variables analyzed. The stress score showed statistically significant differences $(p=.025)$ in the mindfulness group and the rest of the groups, with the exception of the tai chi group. The mindfulness group had a lower mean average than the rest (as indicated by lower levels of stress), followed by the tai chi group. The control group experienced the highest levels of stress.

The anxiety variable showed statistically significant differences $(p=.023)$ among all groups and the control group. The mindfulness, tai chi and yoga groups had 
Table 2

Intergroup Differences in Relation to Stress, Depression and Anxiety

\begin{tabular}{|c|c|c|c|c|c|c|c|}
\hline Variable & \multicolumn{3}{|c|}{ Mean differences between groups } & $\begin{array}{c}\text { M } \\
\text { Cuadr. }\end{array}$ & $F$ & $p$ & $\eta^{2}$ \\
\hline Stress & $\begin{array}{l}\mid \text { Mindfulness-Control|** } \\
\mid \text { Mindfulness-Yogal* }\end{array}$ & $\begin{array}{l}\text { IYoga-Controll } \\
\text { |Mindfulness-Taichíl }\end{array}$ & $\begin{array}{l}\text { ITaichí-Controll| } \\
\text { |Yoga-Taichíl }\end{array}$ & 94.19 & 2.82 & .025 & .034 \\
\hline Anxiety & $\begin{array}{l}\text { |Mindfulness-Control|** } \\
\text { Mindfulness-Yogal }\end{array}$ & $\begin{array}{l}\text { |Yoga-Control|** } \\
\text { |Mindfulness-Taichíl }\end{array}$ & $\begin{array}{l}\text { ITaichí-Control|** } \\
\text { |Yoga-Taichíl }\end{array}$ & 117.16 & 2.88 & .023 & .035 \\
\hline Depression & $\begin{array}{l}\text { IMindfulness-Controll } \\
\text { |Mindfulness-Yogal }\end{array}$ & $\begin{array}{l}\text { |Yoga-Control|*| } \\
\text { |Mindfulness-Taichíl }\end{array}$ & $\begin{array}{l}\text { ITaichí-Controll } \\
\text { |Yoga-Taichí|* }\end{array}$ & 217.34 & 8.43 & .001 & .096 \\
\hline Dass Total & $\begin{array}{l}\text { |Mindfulness-Control|** } \\
\text { |Mindfulness-Yogal }\end{array}$ & $\begin{array}{l}\text { |Yoga-Control|*| } \\
\text { |Mindfulness-Taichí| }\end{array}$ & $\begin{array}{l}\text { ITaichí-Control|* } \\
\text { |Yoga-Taichíl }\end{array}$ & 910.02 & 4.12 & .003 & .049 \\
\hline
\end{tabular}

$* p<.05$. ** $p<.01$.

lower mean averages than the control group, indicating reduced levels of anxiety.

The depression variable showed significant differences $(p=.001)$ among the groups in the post-test phase. Differences were observed between the yoga group and the tai chi and control groups, with the yoga group showing the lowest levels of depression.

Finally, the DASS total showed significant differences among the groups $(p=.003)$. The post hoc test (Tukey Kramer) determined that the greatest differences were found between the mindfulness group and the control group. Participants in the mindfulness group had a lower mean average (resulting in an improved mental state) than participants from the control group, which had a higher mean average. There were also differences between the yoga and tai chi groups in comparison with the control group, where the former two had a lower mean average than the latter.

The pretest and post-test scores in the control group showed no statistically significant differences in any of the variables evaluated, as illustrated in Table 1. When the same analysis was done to evaluate the scores for the mindfulness group, significant differences were found only in the stress variable, which showed a higher mean average in the pretest phase $(M=10.89$, $S D=4.18, n=84)$ than the post-test phase $(M=9.36, S D=3.89, n=84)$ $t(83)=2.755, p=.007, d=0.378$, 95\% IC [,423, 2,623]. As a result, stress levels had been significantly reduced among participants in the mindfulness program. 
When considering the effect size, the mindfulness program had a moderate impact on participants' level of stress. Yet, despite the fact that this group showed no significant differences in the pretest and post-test measurements for the remaining variables, the mean averages did improve at the conclusion of the intervention. Furthermore, the effect size in interactions where no significant differences were observed between the pretest and posttest measurements in the mindfulness group showed that the impact of the program was mild across all variables, with the exception of depression. The tai chi intervention showed statistically significant differences only in the anxiety variable when comparing pretest and post-test measurements. In this case, there was also a reduction of anxiety, as indicated by a higher mean average in the pretest measurement $(M=12.96, S D=8.42$, $n=62$ ) than the post-test measurement $(M=10.12, S D=5.67, n=62)$ $t(61)=2.905, p=.005, d=0.395$, $95 \%$ IC $[0,884,4,792]$. As a result, there was an equal statistically significant reduction in stress levels in participants from the tai chi program. Taking the effect size into consideration, this program had a moderate effect on this variable, and also contributed to improvements (while not significant) in anxiety and the total score. The yoga group had similar results with a moderate reduction in anxiety, according to the effect size. The pretest meas- urement was greater $(M=12.96$, $S D=8.63, n=77)$ than the post-test measurement $(M=9.79, S D=7.86$, $n=77) t(76)=3.670, p<.001$, $d=0.399,95 \%$ IC $[1,449,4,888]$.

Finally, a multivariate analysis was conducted to evaluate the influence of gender and age on the benefits of the intervention. A MANCOVA analysis concluded that there were no statistically significant differences due to age $[p=.976, F(72.00)<1$, Lambda de Wilks $\left.=.845 ; \eta^{2}=.041\right]$, gen$\operatorname{der}[p=.798, F(4.00)<1$, Lambda de Wilks=.994; $\left.\eta^{2}=.006\right]$ or Gender*Age interaction $[p=.056$, $F(32.00) 1.45$, Lambda de Wilks $\left.=.855 ; \eta^{2}=.038\right]$. Therefore, it can be concluded that the effect of the programs was the same for all participants regardless of gender or age.

\section{Discussion}

The present study compared three widely popular mind-body interventions: yoga, tai chi and mindfulness, against a control group.

The results indicated that the three experimental techniques were effective in some of the variables evaluated versus the control group, which showed no decrease in the variables, and even an increase in depression symptoms. These results confirmed what has been clearly demonstrated: mind-body interventions can improve a person's level of mental health when com- 
pared to those who do not practice these techniques (i.e. Mehling et al., 2011). The results also support the hypothesis of this study: the three techniques based on mind-body interventions (tai chi, yoga and mindfulness) contributed to a reduction in emotional stress levels in future teachers when compared to the control group.

Specifically, differences were observed in the variables evaluated according to the type of practice. The lack of effectiveness of some interventions on all of the variables evaluated was also observed in the previous study, which compared Brain Wave Vibration training, Iyengar yoga and mindfulness (Bowden, Gaudry, An, \& Gruzelier, 2011). In this sense, interventions that stress postural control, like yoga and tai chi, resulted in a greater improvement in students' anxiety levels. Mindfulness showed a decrease in anxiety, but it was not statistically significant.

With regard to stress, the study confirmed that mindfulness is an intervention that reduces its levels, which has been demonstrated in various studies (Fjorback, Arendt, Ornbøl, \& Walach, 2011). This is especially relevant in the sample of university students, as there is significant evidence indicating that elevated stress levels can lead to various problems in students including difficulties with attention and concentration, memorization, problem solving, low productivity and poor academic performance
(Pérez, Martín, Borda, \& Del Río, 2003).

Conversely, yoga and tai chi also reduced stress levels in participants, as opposed to the control group; however, the difference was not significant. This result falls in line with recent studies that demonstrate that, while mind-body interventions share elements in common (Mehling et al., 2011), there are differences in specific aspects of each program. For example, when MSBR was compared with Compassion Cultivation training (CCT) (a standardized program consisting of nine sessions with a similar structure to that of MSBR, but with a specific focus on developing compassion), a decrease in stress levels was observed in both programs, but only CCT showed an increase in levels of compassion and identification with all humanity (Brito, 2014). Other studies also support the notion that there are differences according to the practices used, even within the same intervention like MSBR (Sauer-Zavala, Walsh, Eisenlohr-Moul, \& Lykins, 2013).

With regard to depression symptoms, no changes were observed in any of the groups. However, as Table 1 illustrates, the mean averages of all groups were low, which could have affected the expected outcome, as some fluctuations in mood are to be expected. Given this, we believe it would be ill-advised to conclude that these interventions do not have any effect on depression symptoms. In fact, their effect has been widely 
reported in clinical populations (Hofmann et al., 2010; Louie, 2014; Uebelacker et al., 2010). Therefore, it would be beneficial to replicate the study in the future with students that manifest these types of problems.

While these results can be generalizable to the university population as a whole, special relevance is given to those careers where future professionals will be subjected to a high level of stress, such as teachers or health professionals (Extremera et al., 2010; Figueiredo-Ferraz, GilMonte, Ribeiro, \& Grau-Alberola, 2013; Moriana \& Herruzo, 2004). In this sense, these interventions can be seen as a strategy to enhance self-care resources for staff and promote mental health among profes- sionals (Christopher, Christopher, Dunnagan, \& Schure, 2006; Franco et al., 2010) and students, in the case of teachers, when faced with, for example, high levels of stress during exam periods (Álvarez et al., 2012; Langer et al., 2015; Mendelson et al., 2013; Zenner, Herrnleben-Kurz, \& Walach, 2014).

One limitation of the present study was that no follow-up was done to determine if the results lasted over time. Also, while this study focused on malaise (negative effects), it would have been relevant to study other variables related to the students' quality of life or wellness. Conversely, it would have been important to determine if the participants had prior experience with mind-body interventions.

\section{References}

Álvarez, J., Aguilar, J. M., \& Lorenzo, J. J. (2012). La ansiedad ante los exámenes en estudiantes universitarios: Relaciones con variables personales y académicas. Electronic Journal of Research in Educational Psychology, 10(1), 333-354.

Baer, R. (2003). Mindfulness training as a clinical intervention: A conceptual and empirical review. Clinical Psychology: Science and Practice, 10, 125-143. doi: 10.1093/clipsy/bpg015

Bowden, D., Gaudry, C., An, S. C., \& Gruzelier, J. (2012). A comparative randomised controlled trial of the effects of brain wave vibration train- ing, Iyengar yoga, and mindfulness on mood, well-being, and salivary cortisol. Evidence-Based Complementary and Alternative Medicine, 2012, 1-13. doi: $10.1155 / 2012 / 234713$

Brito, G. (2014, October). Personal and relational effects of compassion cultivation training and mindfulness-based stress reduction: A controlled study in Santiago de Chile. Poster presented at International Symposium for Contemplative Studies, Boston, MA, USA. doi: 10.13140/2.1.4429.6002

Canneti, R. (2008). Energía vital en el hombre. Yoga - Tai-Chi - Chi-Kung - 
Meditación. Madrid: Entrelíneas editores.

Christopher, J. C., Christopher, S. E., Dunnagan, T., \& Schure, M. (2006). Teaching self-care through mindfulness practices: The application of yoga, meditation, and qigong to counselor training. Journal of Humanistic Psychology, 46, 494-509. doi: $10.1177 / 0022167806290215$

De la Fuente, J., Franco, C., \& Mañas, I. (2010). Efectos de un programa de entrenamiento en conciencia plena (mindfulness) en el estado emocional de estudiantes universitarios. Estudios sobre Educación, 19, 31-52.

Dick, A. M., Niles, B. L., Street, A. E., DiMartino, D. M., \& Mitchell, K. S. (2014). Examining mechanisms of change in a yoga intervention for women: The influence of mindfulness, psychological flexibility, and emotion regulation on PTSD symptoms. Journal of Clinical Psychology, 70(12), 1170-1182. doi: 10.1002/ jclp. 22104

Extremera, N., Rey, L., \& Pena, M. (2010). La docencia perjudica seriamente la salud. Análisis de los síntomas asociados al estrés docente. Boletín de Psicología, 100, 43-54.

Figueiredo-Ferraz, H., Gil-Monte, P. R., Ribeiro, B., \& Grau-Alberola, E. (2013). Influence of a cognitive behavioural training program on health: A study among primary teacher. Revista de Psicodidáctica, 18(2), 343-356. doi: 10.1387/RevPsicodidact.6995

Fjorback, L., Arendt, M., Ornbøl, E., \& Walach, H. (2011). Mindfulness-based stress reduction and mindfulness based cognitive therapy: A systematic review of randomized controlled trials. Acta Psychiatrica Scandinavica, 124, 102-119.doi: 10.1111/j.16000447.2011.01704.x
Fonseca, E., Paino, M. M., Lemos, S., \& Muñiz, J. (2010). Propiedades psicométricas de la Depression Anxiety and Stress Scales-21 (Dass-21) en universitarios españoles. Ansiedad y Estrés, 16(2), 215-226.

Franco, C. (2010). Reducción de la percepción del estrés en estudiantes de Magisterio mediante la práctica de meditación fluir. Apuntes de Psicología, 27, 99-109.

Franco, C., Mañas, I., Cangas, A. J., Moreno, E., \& Gallego, J. (2010). Reducción del malestar psicológico en docentes mediante un programa de entrenamiento en mindfulness. The Spanish Journal of Psychology, 13, 655666.

Gallego, J., Aguilar-Parra, J. M., Cangas, A. J., Langer, A. I., \& Mañas, I. (2014). Effects of a mindfulness program on stress, anxiety and depression in university students. The Spanish Journal of Psychology, 17, 1-6. doi:10.1017/sjp.2014.102

Hofmann, S., Oh, D., Sawyer, A., \& Witt, A. (2010). The effect of mindfulnessbased therapy on anxiety and depression: A meta-analytic review. Journal of Consulting and Clinical Psychology, 78(2), 169-183. doi: 10.1037/a0018555

Kabat-Zinn, J. (1990). Full catastrophe living: using the wisdom of your body and mind to face stress, pain and illness. New York: Hyperion.

Kabat-Zinn, J. (1994). Wherever you go, there you are: mindfulness meditation in everyday life. New York: Hyperion.

Langer, A. I., Cangas, A. J., \& Gallego, J. (2010). Mindfulness-based intervention on distressing hallucination-like experiences in a nonclinical sample. Behavior Change, 27, 176-183. doi: 10.1375/bech.27.3.176

Langer, A. I., Ulloa, J. V., Cangas, A. J., Rojas, G., \& Krause, M. (2015). In- 
tervenciones basadas en mindfulness en educación secundaria: Una revisión sistemática cualitativa. Estudios de Psicología, 36(3), 533-570. doi: 10.1080/02109395.2015.1078553.

Lee, L. Y., Chong, Y. L., Li, N. Y., Li, M. C., Lin, L. N., Wong, L. Y., ... Man, S. Y. (2013). Feasibility and effectiveness of a Chen-style Tai Chi programme for stress reduction in junior secondary school students. Stress Health, 29(2), 117-124. doi: 10.1002/smi.2435

Louie, L. (2014). The effectiveness of yoga for depression: A critical literature review. Issues in Mental Health Nursing, 35(4), 265-276. doi: 10.3109/01612840.2013.874062

Lovibond, S. H., \& Lovibond, P. F. (1995). Manual for the Depression Anxiety Stress Scales. Sydney: Psychology Foundation of Australia.

Mehling, W. E., Wrubel1, J., Daubenmier, J. J., Price, C. J., Kerr, C. E., Silow, T., ... Stewart, A. L. (2011). Body Awareness: A phenomenological inquiry into the common ground of mind-body therapies. Philosophy, Ethics, and Humanities in Medicine, 6, 1-6. doi: 10.1186/1747-5341-6-6

Mendelson, T., Dariotis, J. K., Feagans Gould, L., Smith, A., Smith, A., Gonzalez, A., \& Greenberg, M. T. (2013). Implementing mindfulness and yoga in urban schools: A community-academic partnership. Journal of Children's Services, 8, 276-291. doi: 10.1108/JCS-04-2013-0016

Moriana, J. A., \& Herruzo, J. (2004). Estrés y burnout en profesores. International Journal of Clinical and Health Psychology, 4(3), 597-621.

Oman, D., Shapiro, S. L., Thoresen, C. E., Plante, T. G., \& Flinders, T. (2008). Meditation lowers stress and supports forgiveness among college students: A randomized controlled trial. Journal of
American College Health, 56(5), 569578. doi: 10.3200/JACH.56.5.569-578

Pérez, M., Martín, A., Borda, M., \& Del Río, C. (2003). Estrés y rendimiento académico en estudiantes universitarios. Cuadernos de Medicina Psicosomática y Psiquiatría de Enlace, 67/68, 26-33.

Quintero, E., Rodríguez, M. C., Guzmán, L. A., Llanos, O. L., \& Reyes, A. (2011). Effects of a program of yogahatha on psychological variables, functional, physical in patients with Alzheimer type dementia. Psychologia, Avances de la Disciplina, 5, 45-56.

Salmon, P., Lush, E., Jablonski, M., Sandra, E., \& Sephton, S. E. (2009). Yoga and mindfulness: Clinical aspects of an ancient $\mathrm{mind} /$ body practice. Cognitive and Behavioral Practice, 16, 59-72. doi: 10.1016/j.cbpra.2008.07.002

Sauer-Zavala, S. E., Walsh, E. C., Eisenlohr-Moul, T. A., \& Lykins, E. L. B. (2013). Comparing mindfulness-based intervention strategies: Differential effects of sitting meditation, body scan, and mindful yoga. Mindfulness, 4, 383388. doi: 10.1007/s12671-012-0139-9

Segal, Z., Williams, J., \& Teasdale, J. (2002). Mindfulness based cognitive therapy for depression. New York: Guilford.

Tsung-Hwa, J. (2001). El Tao del Taiji Quan. Cómo mejorar la salud y el bienestar personal. México: Árbol Editorial, S.A.

Uebelacker, L. A., Epstein-Lubow, G., Gaudiano, B. A., Tremont, G., Battle, C. L., \& Miller, I. W. (2010). Hatha yoga for depression: Critical review of the evidence for efficacy, plausible mechanisms of action, and directions for future research. Journal of Psychiatric Practice, 16, 22-33. doi: 10.1097/01.pra.0000367775.88388.96

Vernet, O., \& Nicolaci, G. (2013). Efectos del yoga sobre la salud global, la ten- 
sión muscular y el estrés académico. Revista Psicología, 30, 87-106.

Wang, C., Collet, J. P., \& Lau, J. (2004). The effect of tai chi on health outcomes in patients with chronic conditions. A systematic review. Archives Internal Medicine, 164, 493-501. doi:10.1001/ archinte.164.5.493

Yeh, G. Y., Wang, C., Wayne, P. M., \& Phillips, R. S. (2008). The effect of tai chi exercise on blood pressure: A systematic review. Preventive Cardiology, 11, 82-89. doi: 10.1111/j.17517141.2008.07565.x
Zheng, G., Lan, X., Li, M., Ling, K., Lin, H., Chen, L., ... Fang, Q. (2014). The effectiveness of Tai Chi on the physical and psychological well-being of college students: A study protocol for a randomized controlled trial. Trials, 15, 1-9. doi: 10.1186/1745-6215-15129

Zenner, C., Herrnleben-Kurz, S., \& Walach, H. (2014). Mindfulness-based interventions in schools-a systematic review and meta-analysis. Frontiers in Psychology, 5, article 603, 1-20. doi: 10.3389/fpsyg.2014.00603 
José Gallego, teacher of Physical Education in the Education Department of Almería University. PhD in Physical Education from Granada University. His research focuses on the psychological benefits associated with physical activity and sport for people in situations of social exclusion. He is an expertise in implementing intervention programs as mindfulness, yoga, tai chi and adapted physical activity programs.

José M. Aguilar-Parra, Associate teacher in the Department of Evolutionary Psychology and Education at Almería University. Author of numerous publications in impact journals about benefits of physical activity programs on physical and mental health of people. Currently they are being developed various studies with mindfulness in different contexts.

Adolfo J. Cangas, Professor of Psychology at Almería University. He is co-editor of the Journal Psychology, Society \& Education. Author of more than a hundred publications related to new interventions in psychotherapy, Severe Mental Illness and Psychopathology. Currently he is conducting several studies related to mindfulness in different clinical and educational contexts.

Antonio Rosado, Professor of Psychology at Lisbon University. Author of more than a hundred publications in impact journals related to the benefits of physical activity and sports in people. Currently he conducts researches about the influence of physical activity programs in education.

Álvaro I. Langer, clinical psychologist and $\mathrm{PhD}$ in Psychology and mindfulness instructor. His areas of interest are phenomenology of psychotic experiences, the study of mindfulness-based interventions, and the impact of social and cultural practices in promoting the psychological well-being. He is currently a postdoctoral researcher at Catholic University of Chile. 
